\title{
Caffeine as A Natural Corrosion Inhibitor for Mild Steel in Nacl Solution
}

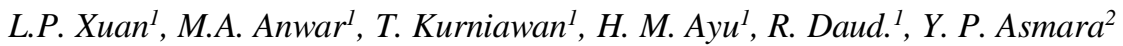 \\ ${ }^{1}$ Faculty of Mechanical Engineering, Universiti Malaysia Pahang, 26600 Pekan, Pahang, Malaysia \\ ${ }^{2}$ Inti International University, Faculty of Engineering and Quantity Surveying, Nilai 71800 Negeri Sembilan, Malaysia \\ Email: azimanwar@rocketmail.com
}

\begin{abstract}
Corrosion inhibitors are substances that added to the environment in small concentration and can effectively reduce the corrosion rate that of a metal surface. Natural inhibitors are one types of inhibitor being researched as it brings less environmental impact on the environment. This research was focused on the application of caffeine as inhibitor for corrosion of mild steel in seawater condition. The objective of this project was to develop the relationship between caffeine concentration on the corrosion of mild carbon steel in both static and moving solution contained 3.5-wt\% $\mathrm{NaCl}$. Three types of solution were prepared, which are $\mathrm{NaCl}$ without addition of caffeine, $\mathrm{NaCl}$ with 1 -wt $\%$ of caffeine and $\mathrm{NaCl}$ with 2 -wt\% of caffeine. Corrosion testing was carried out by weight loss measurement. The microstructures of corroded mild steel specimens were observed under optical microscope. The experimental results indicated that by adding caffeine into the environment medium, weight loss of mild steel specimen was reduced. The corrosion rate of specimens was decreased when more caffeine was added to the environment. From optical microscopic observation, caffeine performed its inhibition effect likely by forming a protective layer which acts as barrier to prevent further corrosion of mild steel in $\mathrm{NaCl}$ solution.
\end{abstract}

Keywords: Caffein, natural corrotion, NaCL

Paper type Research paper

\section{INTRODUCTION}

Metal corrosion is a costly fact of life in the oil and gas industry [1]. Deterioration of the metal components surface that used in offshore production processes can result in premature and sudden failure with the risk of costly, unscheduled downtime and the threat of hydrocarbon leakage. According to the research conducted by National Association of Corrosion Engineers (NACE) International, the total annual cost of corrosion in the oil and gas production industry is estimated to be $\$ 1.372$ billion, which broken down into $\$ 589$ million in surface pipeline and facility costs, $\$ 463$ million annually in downhole tubing expenses, and another $\$ 320$ million in capital expenditures related to corrosion [2]. Corrosion inhibitors is a substance when added in a small concentration to an environment, can reduce the corrosion rate of a metal exposed to that environment [3]. With an issue as significant in terms of both expenditure and productivity in oil and gas industry, corrosion inhibition is implemented as solution to these problems. Currently, chromate compounds function as anodic corrosion inhibitors which is depresses the oxidation process of metals [4]. Nevertheless, these chemical corrosion inhibitors are expensive and resulted in high cost in corrosion inhibitor consumption field [5]. Besides a big amount of money is needed for application, chemical inhibitors also possess environmental toxicity which violates the environmental regulation [6]. Therefore, these problems were then prompted the search for green corrosion inhibitors [7]. Green corrosion inhibitors are less expensive as compare to chemical inhibitors and they are readily available. Besides, natural inhibitors are biodegradable, which they do not contain heavy metals or other toxic compounds [5]. Hence, they are environmentally friendly and ecologically acceptable.

Natural substances that contain amino acids are used in many types of research as the natural corrosion inhibitors [8-10]. Experiment and theoretical study on corrosion inhibition of copper in $1 \mathrm{M}$ of nitric acid by using amino acids such as Glutamine, Leucine, Methionine and Threonine were conducted [11]. Researches by using extracts from Olive leaves, leaf extracts of Sanservieria trifasciata and jojoba oil were also conducted to test on their anticorrosive action [12]. Besides, there are also researches using caffeine as natural inhibitors for corrosion inhibition. It is because caffeine is inexpensive, abundant and easy to obtain. It contains high percentage of amino acids which are capable in corrosion inhibition. Therefore, further researches on corrosion inhibition activity by using caffeine as inhibitor are required to carry out.

Green inhibitors are widely used in current research for corrosion control activities as its environmentally friendly characteristics. In the last few years, several papers have been published by Umoren and Obot's group about the 

evaluation of plant extracts such as ethanolic extracts from leaves of Chlomolaena Odorata L. (LECO) on corrosion inhibition [13]. However, minimal data are explained about the inhibitive action of caffeine towards corrosion. Therefore, further research on corrosion inhibition activity by using caffeine is conducted as the main purpose of this project.

The concentration of the corrosion inhibitors added can vary the corrosion rate of metal specimens. The higher concentration of corrosion inhibitors resulted in the slower corrosion rate of metal specimens and higher inhibitor efficiency as result. However, over corrosion inhibitors concentration can be a waste. Besides, flowrate of the medium can affect the corrosion rate and inhibitor efficiency too. Lower flow rate can increase the corrosion inhibitors efficiency and vice versa. Therefore, performance of caffeine as corrosion inhibitors with different composition is evaluated as the main purpose of this project.

\section{METHOD}

\section{Sample preparation}

Medium carbon steel specimens with $25 \mathrm{~mm}$ in diameter and $8 \mathrm{~mm}$ thick were used for this experiment, as shown in Figure 2.1. The specimens were then grinding by using Okamoto precision surface grinder to get a smooth surface and then undergoing fine grinding and polishing by using Buehler Handimet 2 roll grinder and Metkon Focipol 2V grinder and polisher with a 600-grit finish to get rid of tiny rust appeared on the steel rod and removed any scratches appeared on the surface. The specimens then washed thoroughly with distilled water and followed by ethanol.

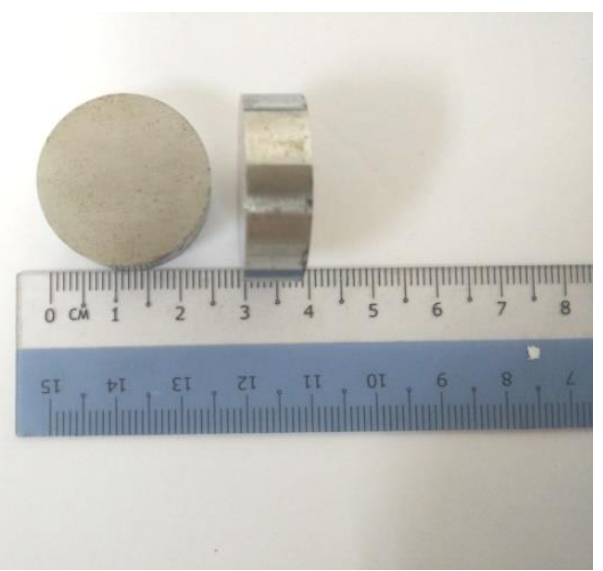

Figure 1. The mild steel specimens with a diameter of $25 \mathrm{~mm}$ and thickness of $8 \mathrm{~mm}$ after grinding process.

\section{Caffeine Solution}

Corrosion inhibitor is added in a small concentration to the environment medium. In this study, 2 different concentration of caffeine solution are prepared to be the corrosion inhibitor which are $1 \%$ and $2 \%$ as shown in Figure 2.2 (1) and (b). In order to prepare salt solution environment with $1 \%$ concentration of corrosion inhibitor, $5 \mathrm{~g}$ of caffeine was prepared and added into the $500 \mathrm{~g}$ dissolved salt solution. For artificial seawater environment with $2 \%$ concentration of caffeine inhibitor, $10 \mathrm{~g}$ of caffeine was prepared and added into the $500 \mathrm{~g}$ sodium chloride solution. These mixtures were then well-stirred by using the hotplate magnetic stirrer.

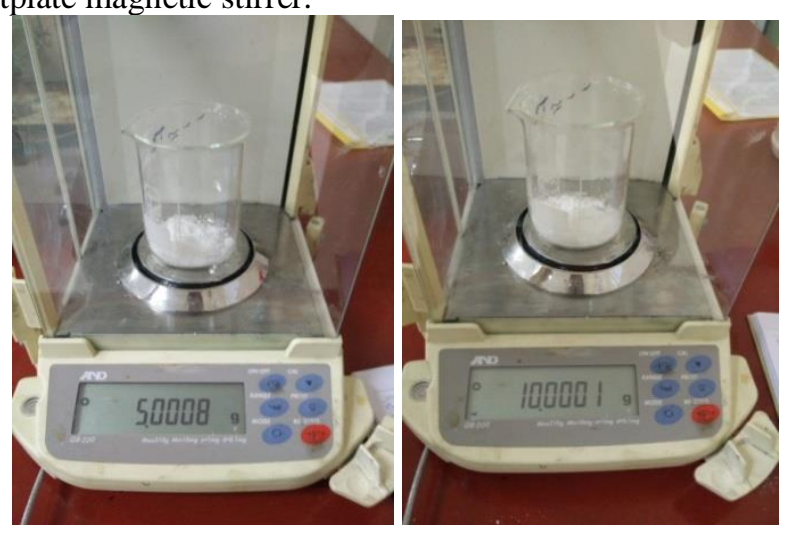

Figure 2. $5.0008 \mathrm{~g}$ of caffeine powder with $1 \%$ concentration of corrosion inhibitor and (b) $10.0001 \mathrm{~g}$ of caffeine powder with $2 \%$ concentration of caffeine inhibitor 


\section{Weight Loss Measurement Method}

Corrosion testing under weight-loss measurement method was carried out with variation of the flowrate of the environment medium. The testing is carried out under static water condition and flowing water condition.

\section{Weight Loss Test under Static Condition}

Three containers of different environment mediums was immersed with three mild steel specimens The weight loss of specimen after 5 days, 8 days and 14 days were recorded. On each data recording day, one specimen from each container was taken out and dried. These mild steel specimens were then immersed into diluted sulphuric acid with concentration of $0.1 \%$ for $60 \mathrm{~s}$ to remove the corrosion products that formed around the specimens' surface. The specimen then washed and dried for weighing process after corrosion test.

\section{Weight Loss Test under Flowing Water Condition}

In order to carry out the effect of flowing water, each container was equipped with a pump and a filter to provide oxygen to the environment medium and make it like the flowing seawater. Each container was immersed with three mild steel specimens with diameter of $25 \mathrm{~mm}$ and thickness of $8 \mathrm{~mm}$ which fully exposed to the environment medium. The corrosion testing was carried out with an immersion period of 14 days. The weight loss of these mild steel specimens after 5 days, 8 days and 14 days were recorded. On each data recording day, one specimen from each container was taken out and dried. These mild steel specimens were then vigorously stirred in diluted sulphuric acid with concentration of $0.1 \%$ for 60 s, in order to remove the oxides and rusts that formed around the specimens' surface. Specimens after vigorously stirred in diluted sulphuric acid were then washed with distilled water and dried so as to carry out the weighing process of specimens after undergo corrosion testing.

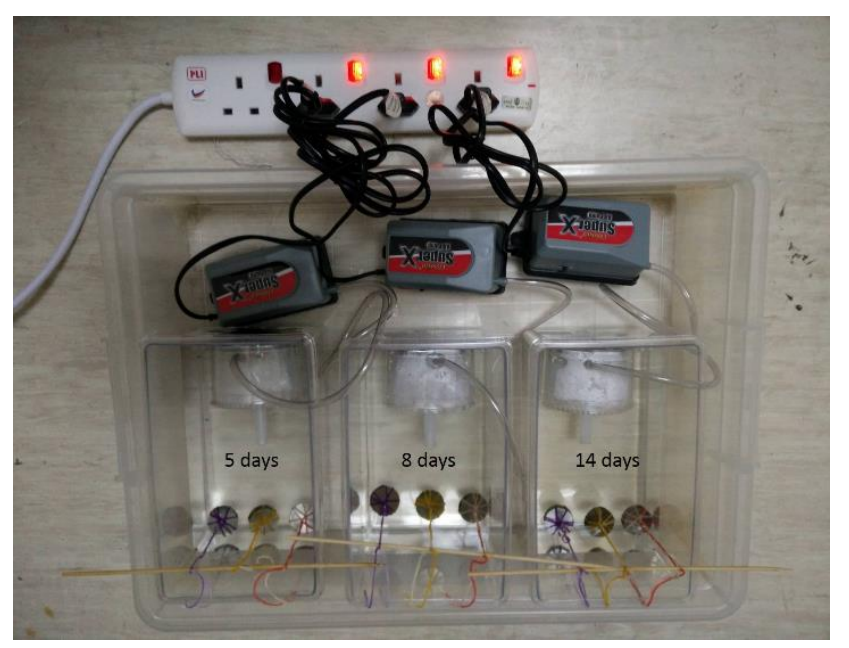

Figure 3. Experimental setup for corrosion testing under flowing water condition with 4, 8 and 14 days respectively.

\section{DISCUSSION}

\section{Weight Loss Measurement Method}

Weight loss measurement method was carried for the first set of experiment to obtain the weight reduced after each specific day and this reduced weight can be used to calculate corrosion rate. Tables 3.1 until 3.3 show the result obtained through weight loss measurement method of the metal specimen respectively on the 5th, 8th and 14th days. E1 represents the environment medium with only salt solution; E2 represents the environment medium containing salt solution and $1 \%$ of caffeine solution while E3 represents the environment medium containing salt solution and $2 \%$ of caffeine solution. Weight loss (WL) is calculated by Eq (1), weight loss percentages (WL\%) are calculated by Eq (2) and corrosion rate (CR) are calculated by using Eq (3). As weight of mild steel specimen in static E1 is set as reference weight, so the values are calculated as following:

$$
W L=\left(W_{0}-W_{i}\right) \times \frac{31.5097}{W_{i}}
$$




$$
W L=\frac{W_{0}-W_{i}}{W_{0}} \times \frac{31.5097}{W_{i}} \times 100 \%
$$

$$
C R=\frac{W L \times K}{\rho \times A \times t}
$$

Material used as the experimental specimens are low carbon steel, which having a density of $7.85 \mathrm{~g} / \mathrm{cm} 3$. The diameter of each low carbon steel specimen is $25 \mathrm{~mm}$ and having a height of $8 \mathrm{~mm}$. The exposed area of the specimen to the environment medium is calculated as in Eq. (3.4) as following.

$$
A=2 \pi r^{2}+2 \pi r h
$$

Since all the low carbon steel specimens having same diameter and same height, so the exposed area to the environment medium is the same, which is equal to $16.1 \mathrm{~cm}^{2}$ calculated by using Eq. (4).

Table $1 \mathrm{~K}$-factor of respective desired corrosion rate unit and area unit.

\begin{tabular}{lcc}
\hline Desired Corrosion Rate Unit $(\boldsymbol{C R})$ & Area Unit $(\boldsymbol{A})$ & $\boldsymbol{K}$-Factor \\
\hline mils/year $(\mathbf{m p y})$ & $\mathrm{in}^{2}$ & $5.34 \times 10^{5}$ \\
mils/year $(\mathbf{m p y})$ & $\mathrm{cm}^{2}$ & $3.45 \times 10^{6}$ \\
millimetres/year $(\mathbf{m m} / \mathbf{y r})$ & $\mathrm{cm}^{2}$ & $8.76 \times 10^{4}$ \\
\hline
\end{tabular}

The inhibitor efficiency, $\mathrm{E}_{\mathrm{w}}$ is obtained by using equation as follow:

$$
E_{W}=\frac{C R_{O}-C R_{i}}{C R_{O}} \times 100 \%
$$

Table 2 Result obtained through weight loss measurement method of the metal specimen after 5 days of the experiment with static seawater.

\begin{tabular}{lcccccc}
\hline $\begin{array}{l}\text { SW } \\
(\mathbf{5 d a y s})\end{array}$ & $\begin{array}{l}\mathbf{W}_{\mathbf{0}} \\
(\mathbf{g})\end{array}$ & $\begin{array}{l}\mathbf{W}_{\mathbf{5}} \\
(\mathbf{g})\end{array}$ & $\begin{array}{c}\mathbf{W L} \\
(\mathbf{g})\end{array}$ & $\begin{array}{c}\text { WL\% } \\
(\mathbf{g})\end{array}$ & $\mathbf{C R}(\mathbf{m m} / \mathbf{y r})$ & $\begin{array}{c}\mathbf{E}_{\mathbf{w}} \\
(\boldsymbol{\%})\end{array}$ \\
\hline $\mathbf{E 1}$ & 31.5097 & 31.4782 & 0.0315 & 0.1000 & 15938.300 & - \\
$\mathbf{E 2}$ & 31.5920 & 31.5639 & 0.0280 & 0.0887 & 14180.936 & 11.0260 \\
$\mathbf{E 3}$ & 31.4308 & 31.4090 & 0.0219 & 0.0695 & 11058.004 & 30.6199 \\
\hline
\end{tabular}

Table 3 Result obtained through weight loss measurement method of the metal specimen after 8 days of the experiment with static seawater.

\begin{tabular}{lcccccr}
\hline $\begin{array}{l}\text { SW } \\
(\text { 8days })\end{array}$ & $\begin{array}{l}\mathbf{W}_{\mathbf{0}} \\
(\mathbf{g})\end{array}$ & $\begin{array}{l}\text { W8 } \\
(\mathbf{g})\end{array}$ & $\begin{array}{c}\text { WL } \\
(\mathbf{g})\end{array}$ & $\begin{array}{c}\text { WL\% } \\
(\mathbf{g})\end{array}$ & $\mathbf{C R}(\mathbf{m m} / \mathbf{y r})$ & $\begin{array}{c}\mathbf{E}_{\mathbf{w}} \\
(\boldsymbol{\%})\end{array}$ \\
\hline E1 & 31.4927 & 31.4613 & 0.0314 & 0.0998 & 9935.174 & - \\
E2 & 31.5918 & 31.5618 & 0.0299 & 0.0947 & 9462.428 & 4.7583 \\
E3 & 31.4604 & 31.4345 & 0.0259 & 0.0825 & 8203.350 & 17.4312 \\
\hline
\end{tabular}


Table 4 Result obtained through weight loss measurement method of the metal specimen after 14 days of the experiment with static seawater.

\begin{tabular}{lcccccr}
\hline $\begin{array}{l}\text { SW } \\
(\mathbf{1 4 d a y s})\end{array}$ & $\begin{array}{l}\mathbf{W}_{\mathbf{0}} \\
(\mathbf{g})\end{array}$ & $\begin{array}{c}\mathbf{W}_{\mathbf{1 4}} \\
(\mathbf{g})\end{array}$ & $\begin{array}{c}\text { WL } \\
(\mathbf{g})\end{array}$ & $\begin{array}{c}\text { WL\% } \\
(\mathbf{g})\end{array}$ & $\begin{array}{c}\text { CR } \\
(\mathbf{m m} / \mathbf{y r})\end{array}$ & $\begin{array}{c}\mathbf{E}_{\mathbf{w}} \\
(\boldsymbol{\%})\end{array}$ \\
\hline E1 & 31.5538 & 31.5174 & 0.0363 & 0.1152 & 6568.518 & - \\
E2 & 31.6305 & 31.5952 & 0.0352 & 0.1112 & 6354.572 & 3.2571 \\
E3 & 31.5034 & 31.4715 & 0.0319 & 0.1013 & 5765.685 & 12.2224 \\
\hline
\end{tabular}

Table 5 Result obtained through weight loss measurement method of the metal specimen after 5 days of the experiment involved with flowing seawater.

\begin{tabular}{lcccccr}
\hline $\begin{array}{l}\text { FW } \\
(\mathbf{5 d a y s})\end{array}$ & $\begin{array}{l}\mathbf{W}_{\mathbf{0}} \\
(\mathbf{g})\end{array}$ & $\begin{array}{l}\mathbf{W}_{\mathbf{5}} \\
(\mathbf{g})\end{array}$ & $\begin{array}{c}\text { WL } \\
(\mathbf{g})\end{array}$ & $\begin{array}{c}\mathbf{W L} \% \\
(\mathbf{g})\end{array}$ & $\mathbf{C R}(\mathbf{m m} / \mathbf{y r})$ & $\begin{array}{c}\mathbf{E}_{\mathbf{w}} \\
(\boldsymbol{\%})\end{array}$ \\
\hline E1 & 31.5837 & 31.5582 & 0.0254 & 0.0805 & 12872.203 & - \\
E2 & 31.4123 & 31.3886 & 0.0238 & 0.0757 & 12028.856 & 6.5517 \\
E3 & 31.4028 & 31.3844 & 0.0185 & 0.0588 & 9341.684 & 27.4275 \\
\hline
\end{tabular}

Table 6 Result obtained through weight loss measurement method of the metal specimen after 8 days of the experiment involved with flowing seawater.

\begin{tabular}{lcccccr}
\hline $\begin{array}{l}\text { FW } \\
\text { (8days) }\end{array}$ & $\begin{array}{l}\mathbf{W}_{\mathbf{0}} \\
(\mathbf{g})\end{array}$ & $\begin{array}{l}\mathbf{W}_{\mathbf{8}} \\
(\mathbf{g})\end{array}$ & $\begin{array}{c}\text { WL } \\
(\mathbf{g})\end{array}$ & $\begin{array}{c}\text { WL\% } \\
(\mathbf{g})\end{array}$ & $\mathbf{C R}(\mathbf{m m} / \mathbf{y r})$ & $\begin{array}{r}\mathbf{E}_{\mathbf{w}} \\
(\boldsymbol{\%})\end{array}$ \\
\hline E1 & 31.5025 & 31.4621 & 0.0404 & 0.1283 & 12778.859 & - \\
E2 & 31.5370 & 31.5003 & 0.0367 & 0.1163 & 11595.818 & 9.2578 \\
E3 & 31.4967 & 31.4710 & 0.0257 & 0.0816 & 8130.622 & 36.3744 \\
\hline
\end{tabular}

Table 7 Result obtained through weight loss measurement method of the metal specimen after 14 days of the experiment involved with flowing seawater.

\begin{tabular}{|c|c|c|c|c|c|c|}
\hline $\begin{array}{l}\text { FW } \\
\text { 14days }\end{array}$ & $\begin{array}{l}W_{0} \\
(g)\end{array}$ & $\begin{array}{l}W_{14} \\
(g)\end{array}$ & $\begin{array}{l}\text { WL } \\
(\mathrm{g})\end{array}$ & $\begin{array}{c}\text { WL\% } \\
\text { (g) }\end{array}$ & $\mathrm{CR}(\mathrm{mm} / \mathrm{yr})$ & $\begin{array}{c}\mathbf{E}_{w} \\
(\%)\end{array}$ \\
\hline E1 & 31.4009 & 31.3401 & 0.0610 & 0.1943 & 11025.014 & - \\
\hline $\mathbf{E 2}$ & 31.5447 & 31.4897 & 0.0549 & 0.1742 & 9927.821 & 9.9518 \\
\hline E3 & 31.5673 & 31.5240 & 0.0432 & 0.1369 & 7810.307 & 29.1583 \\
\hline
\end{tabular}

Table 8 Summary for weight loss in grams of mild steel specimens after corrosion testing in static and flowing environment medium for 5, 8 and 14 days.

\begin{tabular}{lllc}
\hline \multicolumn{1}{c}{ Weight Loss $(\mathbf{g})$} & 5 days & 8 days & 14 days \\
\hline Static E1 & 0.0315 & 0.0314 & 0.0363 \\
Static E2 & 0.0280 & 0.0299 & 0.0352 \\
Static E3 & 0.0219 & 0.0259 & 0.0319 \\
Flowing E1 & 0.0254 & 0.0404 & 0.0610 \\
Flowing E2 & 0.0238 & 0.0367 & 0.0549 \\
Flowing E3 & 0.0185 & 0.0257 & 0.0432 \\
\hline
\end{tabular}

Figure 1 indicates the increment in weight loss as time passes. By comparing in term of the content in the environment medium, weight loss in grams with the presence of caffeine is lower than the weight loss in environment medium without caffeine inhibitor. This effect is hugely marked at a higher concentration of caffeine inhibitor. From the graph, it shows that the weight loss of mild steel specimen for static E1 is higher than that of static E2 and E3. For flowing environment, same scenario happened too where mild steel specimens in flowing E1 loss more weight than that of flowing E2 and E3. 


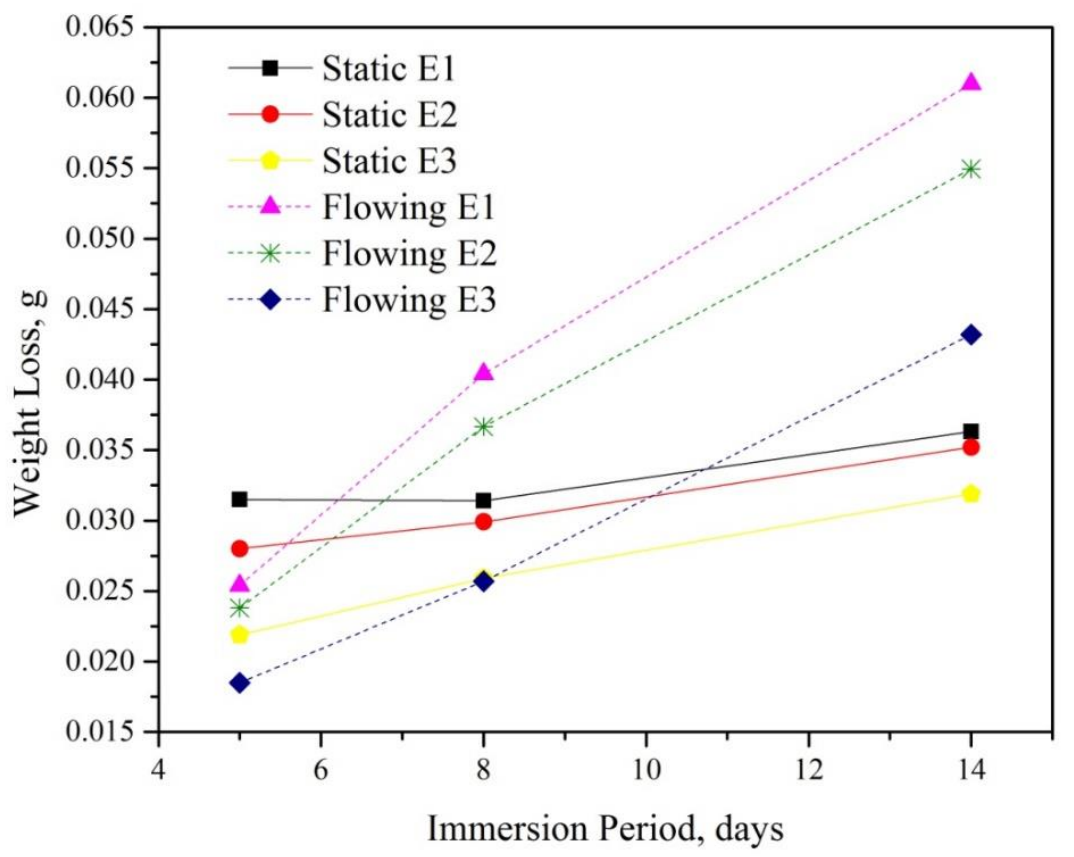

Figure 4. Graph showing the weight loss of the mild steel specimens throughout 2 weeks period immersed in different environment medium.

By comparing in term of the flow velocity of the environment medium, flowing environment medium can be said to result in higher weight loss as shown from the graph. However, weight loss of mild steel specimen in static E1 and E2 is higher than that of flowing E1 and E2 in immersion for 5 days. As for static medium, at the beginning time of immersion, the environment medium caused more corrosion occurred on the surface of mild steel specimens. Flowing medium also caused corrosion on the specimens' surface but since the medium keep on flowing, the chloride and o in $\mathrm{NaCl}$ solution do not perform very well to cause oxidation occurred on the mild steel specimens' surface. For 8 and 14 days of immersion, weight losses of all flowing medium are higher than the weight loss of all static medium. This is because the flowing environment medium can wash away the corrosion product that formed at the surface of mild steel specimens and more corrosion products will start to deposit again on the specimens' surface. While for static environment medium, the corrosion product which formed at the specimens' surface is like a protective film of the specimen, the surrounding environment medium become hardly to cause corrosion on the surface of mild steel specimens.

Table 9 Summary for weight loss in percentage of mild steel specimens after corrosion testing in static and flowing environment medium for 5,8 and 14 days.

\begin{tabular}{llcc}
\hline Weight Loss (\%) & 5 days & 8 days & 14 days \\
\hline Static E1 & 0.1000 & 0.0998 & 0.1152 \\
Static E2 & 0.0887 & 0.0947 & 0.1112 \\
Static E3 & 0.0695 & 0.0825 & 0.1013 \\
Flowing E1 & 0.0805 & 0.1283 & 0.1943 \\
Flowing E2 & 0.0757 & 0.1163 & 0.1742 \\
Flowing E3 & 0.0588 & 0.0816 & 0.1369 \\
\hline
\end{tabular}




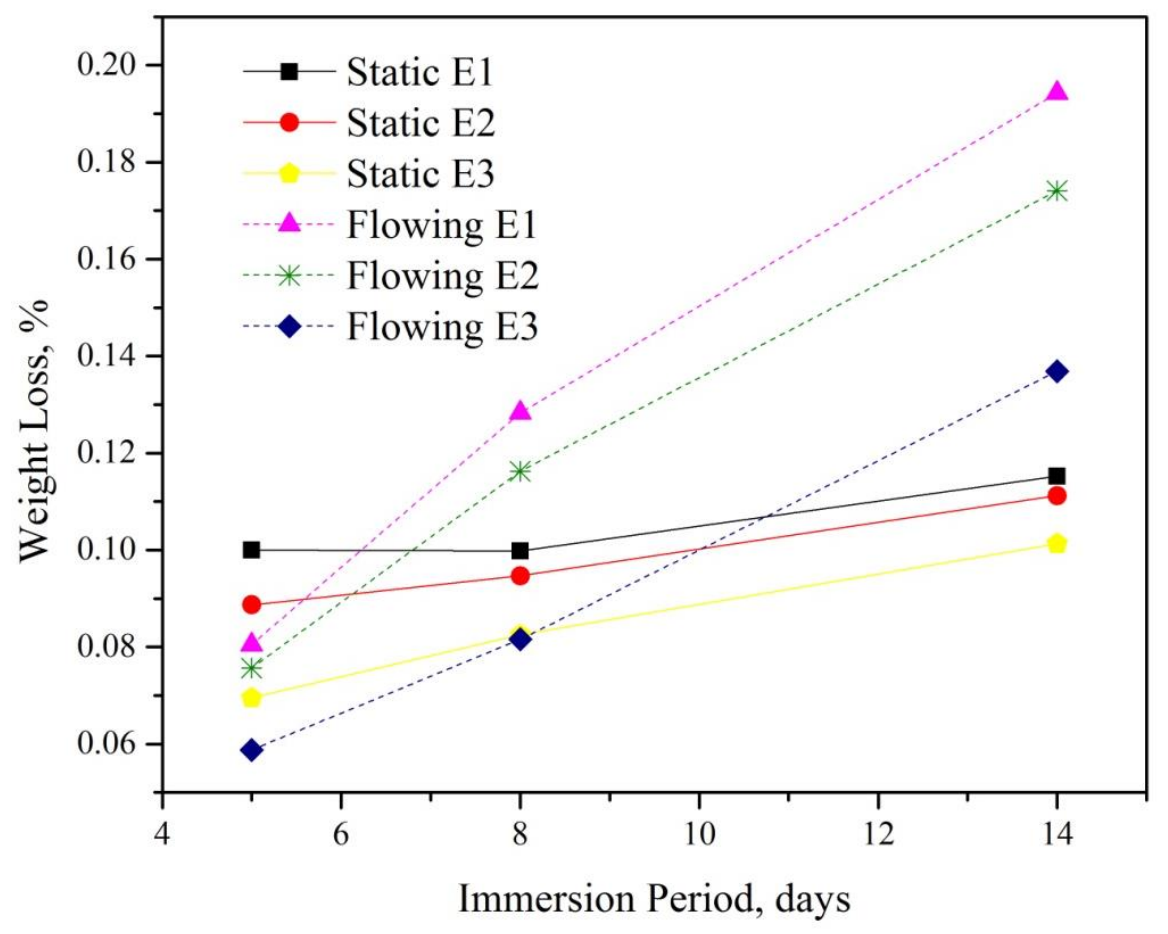

Figure 4. Graph showing weight loss percentage of the mild steel specimens throughout 2 weeks period immersed in different environment medium.

Figure 4 shows obviously that the weight loss percentage of mild steel specimens increase as immersion period passes for both static and flowing environment medium. The presence of caffeine shows inhibitive effect in the corrosion of mild steel specimens. From the graph, specimens in environment medium with more caffeine added lost lesser weight than the specimens in environment medium with a lower concentration of caffeine. The results shows that higher caffeine concentration can give better inhibition towards the mild steel specimens.

Table 10 Summary for corrosion rate of mild steel specimens after corrosion testing in static and flowing environment medium on 5,8 and 14 days.

\begin{tabular}{cccc}
\hline Corrosion Rate $(\mathbf{m m} / \mathbf{y r})$ & 5 days & 8 days & 14 days \\
\hline Static E1 & 15938.300 & 9935.174 & 6568.518 \\
Static E2 & 14180.940 & 9462.428 & 6354.572 \\
Static E3 & 11058.000 & 8203.350 & 5765.685 \\
Flowing E1 & 12872.200 & 12778.860 & 11025.014 \\
Flowing E2 & 12028.860 & 11595.818 & 9927.821 \\
Flowing E3 & 9341.684 & 8130.622 & 7810.307 \\
\hline
\end{tabular}




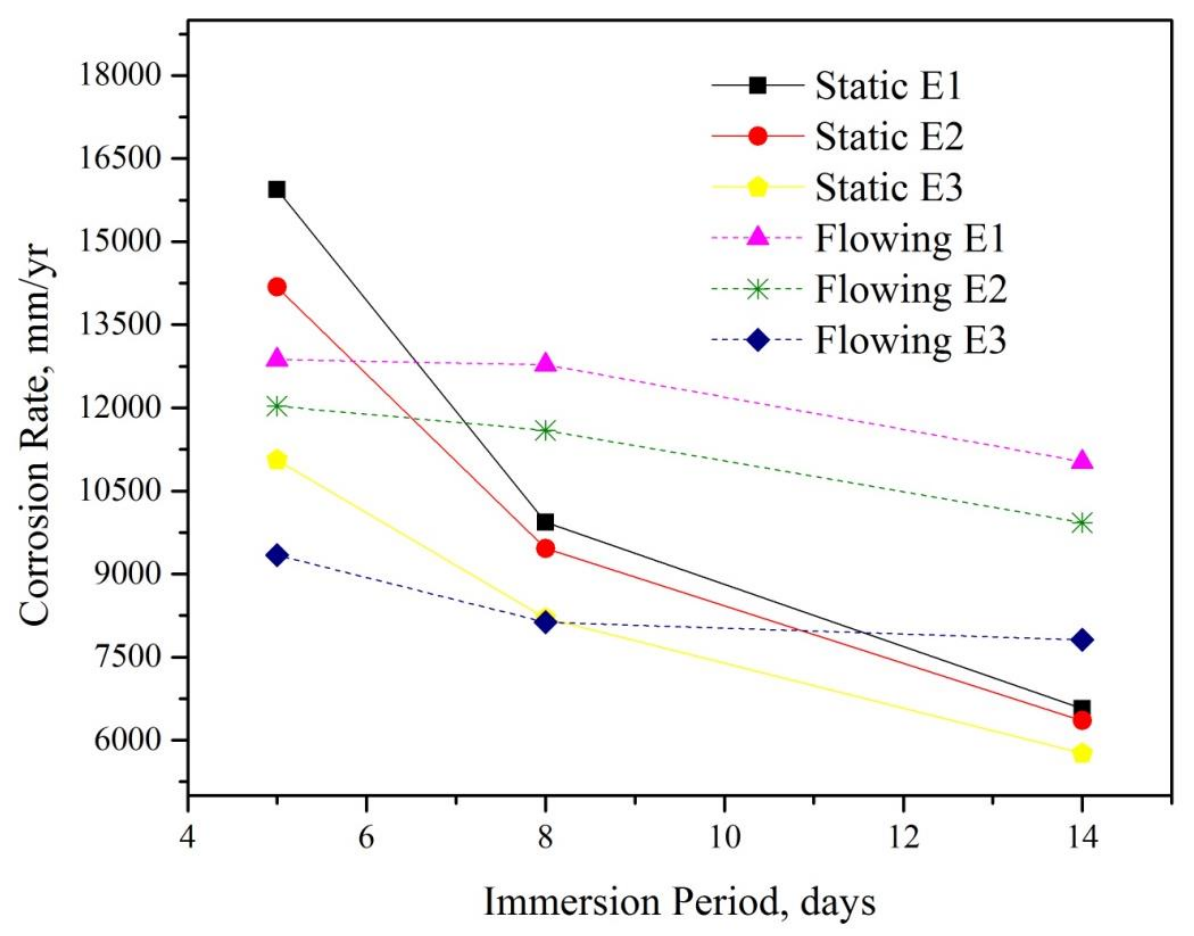

Figure 5. Graph showing corrosion rate of the mild steel specimens throughout 2 weeks period immersed in different environment medium.

As time passes, the corrosion rates of mild steel specimens in both static and flowing environment decrease gradually as shown in figure 4.3. The addition of caffeine to the artificial seawater environment shows a good inhibitive effect towards corrosion of mild steel specimens. A higher concentration of caffeine can even reduce the corrosion rate of specimens to a better stage. From the graph in figure 4.3, it shows that the corrosion rates of mild steel specimens in flowing environment are higher than that of in the static environment regardless of the environment medium content. A flowing environment medium can cause mild steel specimens to corrode at a faster rate than a static environment medium.

\section{Microstructure Observation}

The mild steel specimens being used for testing are observed under magnification of 50x by using an optical microscope. The microscopic images of the specimens before and after corrosion testing were taken and as shown as follows.

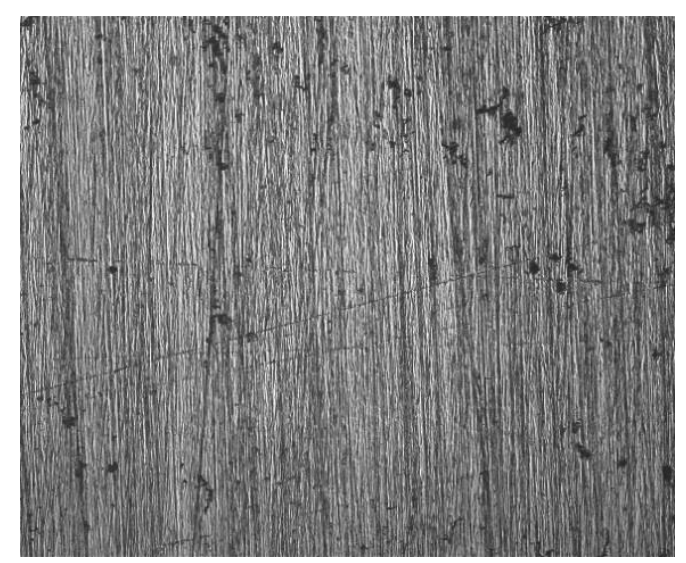

Figure 6. Microscopic image of mild steel specimen before undergoing corrosion testing 
From the optical microscopic image obtained as shown in Figure 6 the microstructure of mild steel specimens before corrosion testing contains ferrite and pearlite crystals. The straight lines shown in the microscopic image are the marks after polishing.

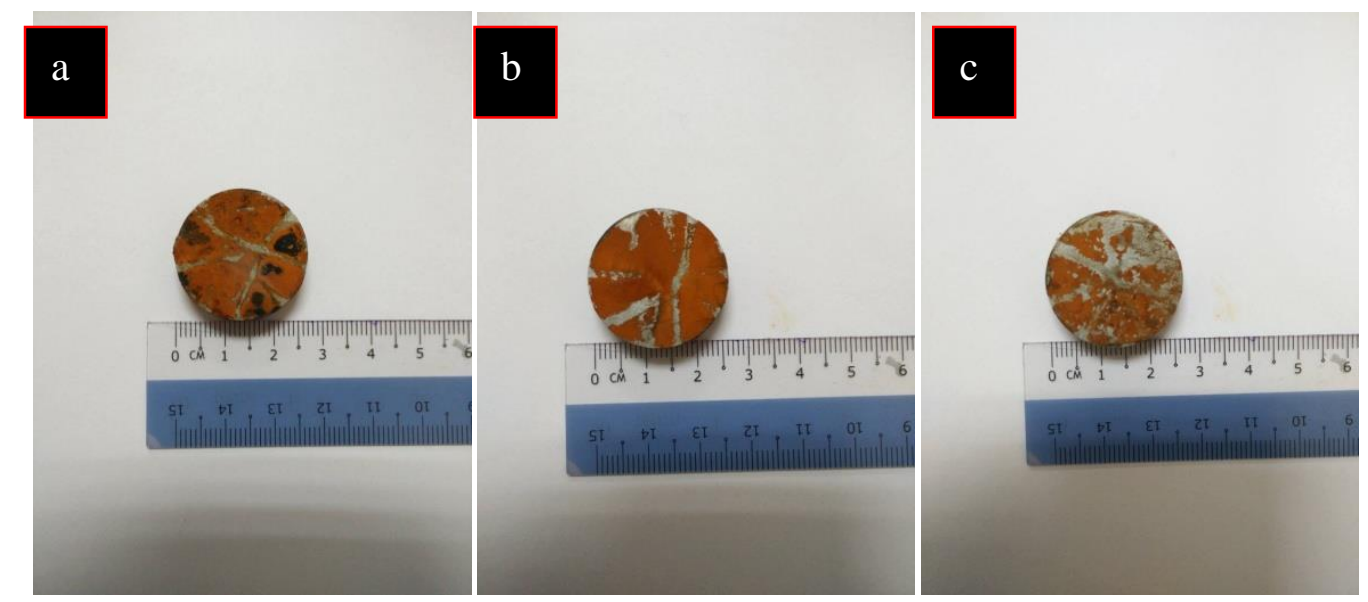

Figure 7 Mild steel specimens after immersion of 8 days in flowing environment medium (a) E1, (b) E2 and (c) E3.

From the observation through naked eye towards the mild steel specimens in figure 7(a), 7(b) and 7(c), the specimen that immersed for 8 days in environment E1 were deposited with more corrosion product than the specimens in environment with caffeine inhibitor. The specimen immersed in environment E3 was deposited with lesser rust particles than the specimen immersed in environment E2. The results shows that higher concentration of caffeine can inhibit the occurrence of corrosion for mild steel specimen in $\mathrm{NaCl}$ solution.
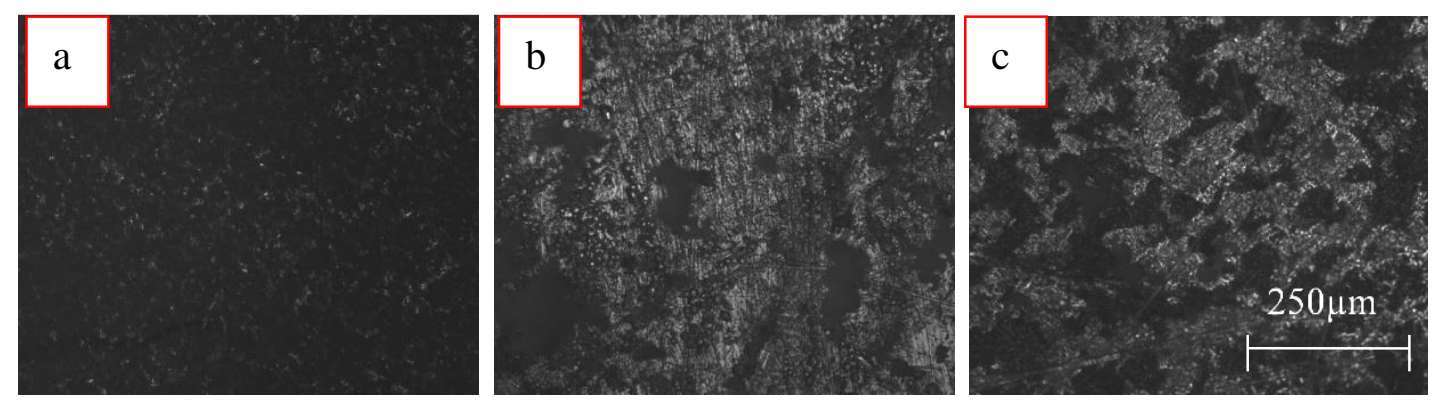

Figure8. Optical microscopic image of mild steel specimen after 8 days of immersion in flowing environment medium (a) E1, (b) E2 and (c) E3.

After immersed in the environment medium for 8 days, rust was formed at the surface of mild steel specimens. In figure 8(a), as a result of the chloride solution, the specimen was highly corroded and an irregular porous surface was generated on the mild steel specimens. With the addition of caffeine, corrosion of mild steel specimens was suppressed and a caffeine-based protective layer was generated on the specimens' surface as shown in figure 8(b) and 8(c). However, this thin layer seems to be brittle and cracks appeared on the surface. 


\section{CONCLUSION}

In conclusion, Caffeine is the corrosion inhibitor which abundant in resource and reasonable in cost consumption. In this research, the main purpose of using caffeine as inhibitor to prevent corrosion for mild steel in oil and gas environment. The corrosion testing was carried out by weight loss measurement method. It shows that caffeine is an excellent corrosion inhibitor for mild steel in seawater condition. Caffeine can perform a good inhibitive effect in both static and flowing environment medium which represents the aphotic zone and photic zone of the ocean respectively. Corrosion rates of mild steel specimens decrease with increasing caffeine concentration in the environmental medium. Flow velocity is also a factor affecting the corrosion rate of mild steel specimens in seawater condition. With similar concentration of caffeine, mild steel specimens in flowing environment medium were corroded in a faster rate than the mild steel specimens in static environment. The inhibition efficiency of caffeine towards corrosion of mild steel in seawater condition increases with increase concentration of caffeine. From image, mild steel specimens undergo corrosion in different environment mediums and orange corrosion product which known rust formed at mild steel surface. Mild steel specimen in environment medium without caffeine was deposited with more corrosion product than the specimen in environment medium with presence of caffeine. By observation through optical microscope, caffeine act likely a protective layer on the surface of mild steel specimens in environment medium with presence of caffeine inhibitor to prevent further corrosion occurred.

\section{References}

[1] R. B. Eckert and T. L. Skovhus, "Advances in the application of molecular microbiological methods in the oil and gas industry and links to microbiologically influenced corrosion,” Int. Biodeterior. Biodegrad., 2018.

[2] P. Rajeev, A. O. Surendranathan, and C. S. N. Murthy, "Corrosion mitigation of the oil well steels using organic inhibitors-A review," J. Mater. Environ. Sci., 2012.

[3] K. Haruna, I. B. Obot, N. K. Ankah, A. A. Sorour, and T. A. Saleh, "Gelatin: A green corrosion inhibitor for carbon steel in oil well acidizing environment," J. Mol. Liq., 2018.

[4] C. G. and A. F., "Corrosion Inhibitors - Principles, Mechanisms and Applications," in Developments in Corrosion Protection, 2014.

[5] S. A. Umoren, A. A. AlAhmary, Z. M. Gasem, and M. M. Solomon, "Evaluation of chitosan and carboxymethyl cellulose as eco friendly corrosion inhibitors for steel," Int. J. Biol. Macromol., 2018.

[6] M. Abd El-Raouf, E. A. Khamis, M. T. H. Abou Kana, and N. A. Negm, "Electrochemical and quantum chemical evaluation of new bis(coumarins) derivatives as corrosion inhibitors for carbon steel corrosion in 0.5 M H2SO4," J. Mol. Liq., 2018.

[7] C. Verma, E. E. Ebenso, I. Bahadur, and M. A. Quraishi, "An overview on plant extracts as environmental sustainable and green corrosion inhibitors for metals and alloys in aggressive corrosive media," Journal of Molecular Liquids. 2018.

[8] K. Zhang et al., "Amino acids modified konjac glucomannan as green corrosion inhibitors for mild steel in HCl solution," Carbohydr. Polym., 2018.

[9] B. El Ibrahimi, A. Jmiai, L. Bazzi, and S. El Issami, "Amino acids and their derivatives as corrosion inhibitors for metals and alloys," Arabian Journal of Chemistry, 2017.

[10] L. Hamadi, S. Mansouri, K. Oulmi, and A. Kareche, "The use of amino acids as corrosion inhibitors for metals: A review," Egyptian Journal of Petroleum, 2018.

[11] K. Barouni, A. Kassale, A. Albourine, O. Jbara, B. Hammouti, and L. Bazzi, "Amino acids as corrosion inhibitors for copper in nitric acid medium: Experimental and theoretical study," J. Mater. Environ. Sci., 2014.

[12] C. Rahal et al., "Olive leaf extract as natural corrosion inhibitor for pure copper in $0.5 \mathrm{M} \mathrm{NaCl}$ solution: A study by voltammetry around OCP," J. Electroanal. Chem., 2016.

[13] I. B. Obot, Z. M. Gasem, and S. A. Umoren, "Molecular level understanding of the mechanism of aloes leaves extract inhibition of low carbon steel corrosion: A DFT approach," Int. J. Electrochem. Sci., 2014. 